\title{
Redundant and Cooperative Interactions between TLR5 and NLRC4 in Protective Lung Mucosal Immunity against Pseudomonas aeruginosa
}

\author{
Leslie Tolle ${ }^{a, b}$ Fu-shin Yuc, d, e Melissa A. Kovach ${ }^{a, b} \quad$ Megan N. Ballinger ${ }^{a, b}$ \\ Michael W. Newstead ${ }^{a, b} \quad$ Xianying Zeng ${ }^{a, b} \quad$ Gabriel Nunez $^{a, b}$ \\ Theodore J. Standiford ${ }^{a, b}$ \\ a Division of Pulmonary and Critical Care Medicine, Department of Medicine, and ${ }^{b}$ Department of Pathology, \\ University of Michigan Medical Center, Ann Arbor, Mich., and Departments of ${ }^{\mathrm{C} O p h t h a l m o l o g y}$, ${ }^{\mathrm{d}}$ Microbiology and \\ eImmunology, Wayne State University, Detroit, Mich., USA
}

\section{Key Words}

Mucosal immunity $\cdot$ Toll-like receptors $\cdot$ Nod-like receptors

\section{Abstract}

Flagellin is the major structural component of flagella expressed by Pseudomonas aeruginosa (PA) and other bacteria. This protein has been shown to activate the Toll-like receptor TLR5 and the Nod-like receptor NIrc4/Ipaf, culminating in the expression of innate cytokines and antimicrobial molecules. In this study, we tested the hypothesis that TLR5 and NIrc4 in combination are required for maximal protective lung innate mucosal immunity against PA. To test this hypothesis, we compared innate immune responses in wild-type (WT) C57B6 mice challenged with PA intratracheally to those observed in mice genetically deficient in TLR5 $\left(\mathrm{TLR5}^{-/-}\right.$) or Nlrc4 ( $\mathrm{Nlrc}^{-/-}$) alone or in combination (TLR5/ $\mathrm{NIrC4}^{-/-}$. . As compared to WT, $\mathrm{TLR}^{-/-}$and $\mathrm{NIrC4}^{-/-}$mice, we observed a significant increase in mortality in TLR5/NIrc4 $4^{-/-}$ mice, which was associated with a $>5,000$-fold increase in lung PA colony-forming units and systemic bacterial dissemination. The increased mortality observed in double-de- ficient mice was not attributable to differences in lung leukocyte influx or lung injury responses. Levels of biologically active IL-1 $\beta$ and IL-18 were reduced in the bronchoalveolar lavage fluid from PA-infected Nlrc4 ${ }^{-/-}$and TLR5/ $/ \mathrm{NIC4}^{-/-}$but not $\mathrm{TLR5}^{-/-}$mice, indicating the requirement for NIrc4-dependent caspase- 1 activation. Similarly, decreased production of biologically active IL-1 $\beta$ and activation of caspase- 1 was observed in PA-stimulated pulmonary macrophages isolated from $\mathrm{Nlrc}^{-/-}$and TLR5/NIrc4 ${ }^{-/-}$but not $\mathrm{TLR5}^{-/-}$ mice, whereas the expression of iNOS and the production of NO were significantly reduced in cells from double-mutant but not single-mutant mice. Collectively, our findings indicate that TLR5 and NIrc4 have both unique and redundant roles in lung antibacterial mucosal immunity, and the absence of both pathogen recognition receptors results in an increase in susceptibility to invasive lung infection.

(c) 2014 S. Karger AG, Basel

The current affiliation of L.T. is the Division of Pulmonary, Allergy, and Critical Care Medicine, Cleveland Clinic Lerner College of Medicine (CCLCM), Case Western Reserve University, Cleveland, Ohio, USA.

\section{KARGER 125}

(c) 2014 S. Karger AG, Base

$1662-811 X / 14 / 0072-0177 \$ 39.50 / 0$

E-Mail karger@karger.com

www.karger.com/jin
Dr. Theodore J. Standiford

Division of Pulmonary and Critical Care Medicine

University of Michigan Medical Center, 109 Zina Pitcher Place, 4065 BSRB

Ann Arbor, MI 48109-2200 (USA)

E-Mail tstandif@umich.edu 


\section{Introduction}

Healthcare-associated pneumonia is the most lethal infection amongst all nosocomial infections and is associated with increased morbidity and longer length of hospital stay when compared to patients with communityacquired pneumonia [1-6]. Pseudomonas aeruginosa (PA) is a flagellated aerobic Gram-negative bacterium that rarely causes pulmonary disease in immunocompetent subjects, but is the second most common nosocomial infection, and pneumonia due to PA is associated with the highest mortality amongst nosocomial infections $[7,8]$. PA expresses several virulence factors, such as flagellin and the type III secretion system, molecules that activate pathogen recognition receptors (PRRs) and promote nuanced innate responses that can be protective or at times deleterious to the host [7,9-11].

Toll-like receptors (TLRs) are a family of type I transmembrane PRRs that are activated by pathogen-associated molecular patterns expressed by a diverse group of microorganisms, resulting in activation of host antimicrobial responses [12-15]. Flagellin, expressed by most strains of PA [16], is the sole activator of TLR5 [17-21]. TLR5 is a MyD88-dependent TLR that is expressed by both myeloid and structural cells, most abundantly in the gut, liver and lung [21]. In the lung, airway and alveolar epithelial cells and alveolar macrophages express TLR5, and the cell-surface expression of TLR5 is upregulated in response to bacteria [22-24]. Upon binding to TLR5, flagellin activates the MyD88 pathway, resulting in NF- $\kappa \mathrm{B}$ nuclear translocation and ultimately increased expression of antimicrobial genes [25-28].

Nod-like receptors (NLRs) are a family of PRRs that recognize intracellular danger signals. During infection, NLRs are activated by a diverse group of pathogen-associated molecular patterns, including the bacterial cell wall components peptidoglycan and muramyl dipeptide, bacterial flagellin and several bacterial toxins [29-33]. Nlrc4 (Ipaf) is a specific NLR that upon binding its ligand activates the inflammasome containing the costimulatory protein ASC and caspase-1 [34]. Interleukin (IL)- 1 family members, including IL- $1 \beta$ and IL-18, are translated as inactive precursor zymogens which are cleaved by caspase- 1 to their active forms, resulting in the generation of host inflammatory responses [25-28]. Nlrc4 is activated by intracellular flagellin. In addition, Nlrc4 binds to and is activated by type III secretion system proteins in a flagellin-independent manner, resulting in caspases-1-mediated IL$1 \beta$ and IL-18 [35-38].
While TLR5 has previously been shown to be dispensable for protective lung mucosal immunity against PA, cooperative interactions between TLR5 and TLR4 are necessary for optimal clearance of this organism [23]. By comparison, Nlrc4 is necessary for effective innate lung responses against the Gram-negative organism Klebsiella pneumoniae. However, this NLR can mediate deleterious inflammation in the setting of PA challenge $[32,39,40]$. Physiological interaction between these two PRRs during bacterial infection has not been investigated. In this study, we sought to identify possible interactions and mechanisms involved during experimental pneumonia due to PA. Our findings indicate that TLR5 and Nlrc4 have both redundant and unique roles in antibacterial mucosal immunity, and the absence of both PRRs results in a substantial increase in susceptibility to invasive lung infection.

\section{Materials and Methods}

\section{Animals}

Specific pathogen-free wild-type (WT) C57BL/6 mice (age and sex matched) were purchased from The Jackson Laboratory (Bar Harbor, Maine, USA). The TLR5 ${ }^{-/}$breeding pairs were originally purchased from A. Aldeman (Institute of Systems Biology, Seattle, Wash., USA). The Nlrc4 ${ }^{-/-}$mice were generated at the University of Michigan (Gabriel Nunez), whereas the TLR5/ $\mathrm{Nlrc}^{-/-}$mice were obtained from Andrew Gewirtz (Emory University). All mice where bred $>5$ generations on a C57BL/ 6 background and housed in specific pathogen-free conditions within the animal care facility (Unit for Laboratory Animal Medicine, University of Michigan, Ann Arbor, Mich., USA) until the day of sacrifice. Animal studies were reviewed and approved by the University Committee on the Use and Care of Animals (University of Michigan).

\section{Bacterial Preparation}

Flagellated P. aeruginosa strain 19660 (American Type Culture Collection, Manassas, Va., USA) was used in our studies. Strains were grown overnight in Difco nutrient broth (BD Biosciences, Franklin Lakes, N.J., USA) at $37^{\circ} \mathrm{C}$ with constant shaking. Bacterial concentrations were then determined by measuring the amount of absorbance at $600 \mathrm{~nm}$ and compared to a predetermined standard curve based on known colony-forming unit $(\mathrm{CFU})$ values. Bacterial cultures were then diluted to the desired concentration for intratracheal (i.t.) inoculation or in vitro stimulation. An aliquot of the inoculated PA suspension serially diluted onto blood agar plates determines the actual dose of bacterial CFU.

\section{i.t. Inoculation}

For i.t. inoculation, mice were anesthetized with an intraperitoneal (i.p.) mixture of ketamine and xylazine. Under sterile conditions, the trachea was exposed using blunt dissection and a $30-\mu \mathrm{l}$ inoculum was administered using a 26-gauge needle. The skin incision was then closed using surgical staples. 
Pulmonary Macrophage Isolation

Pulmonary macrophages (PM) consisting of both alveolar and interstitial lung macrophages were isolated from dispersed lung digest cells by adherence purification as previously described [41]. The purity of these macrophages was $>90 \%$ as determined by forward- and side-scatter characteristics, and F480 and CD11b staining.

Whole Lung and Spleen CFU Determination

Mice were euthanized by $\mathrm{CO}_{2}$ asphyxiation at specified time points and the thoracic cavity was opened under sterile technique. In order to perfuse the cardiopulmonary vasculature, $1 \mathrm{ml}$ of sterile PBS containing $5 \mathrm{~mm}$ EDTA was infused through the right ventricle. Whole lungs and spleens were then removed, taking care to dissect away lymph nodes. Organs were then homogenized separately in $1 \mathrm{ml}$ of sterile PBS with protease inhibitor (Boehringer Mannheim, Indianapolis, Ind., USA). Homogenates were serially diluted 1:5 in sterile PBS and plated on nutrient agar (BD Biosciences) plates to determine CFU.

\section{Bronchoalveolar Lavage}

Bronchoalveolar lavage (BAL) was performed for the collection of BAL fluid (BALF) as previously described. Briefly, the trachea was exposed and intubated using 26-gauge polyethylene tubing. Three 1-ml aliquots of PBS containing $5 \mathrm{~mm}$ EDTA were instilled and aspirated using syringe suctioning. More than $80 \%$ of BALF was retrieved [41].

\section{BALF Leukocyte Analysis}

BALF was centrifuged at $1,500 \mathrm{rpm}$ at $4^{\circ} \mathrm{C}$ for $10 \mathrm{~min}$. Cell-free BALF was separated and aliquoted for murine cytokine, chemokine and albumin ELISA measurements. One milliliter of sterile deionized water was added to each cell pellet and thoroughly mixed for $20 \mathrm{~s}$ in order to lyse red blood cells. To prevent leukocyte lysis, $10 \mathrm{ml}$ of Life Technologies RPMI Medium (Invitrogen, Carlsbad, Calif., USA) was added. Samples were centrifuged again at $1,500 \mathrm{rpm}$ at $4^{\circ} \mathrm{C}$ for $10 \mathrm{~min}$. Supernatant was aspirated off and the cell pellet was resuspended in $250 \mu$ of RPMI (Invitrogen). Cell counts and viability were determined using trypan blue exclusion counting on a hemacytometer. Cytospin slides were prepared to a concentration of $2 \times 10^{4}$ cells/slide and stained with modified Wright-Giemsa stain.

\section{Murine ELISAs for Cytokine/Chemokine Measurement}

Cell-free BALF was analyzed for IL-1 $\beta$, TNF- $\alpha$ and KC/ CXCL1 using mouse DuoSet ELISA kits (R\&D Systems, Minneapolis, Minn., USA) employing a modified double-ligand method. The IL-18 ELISA was purchased from Affymetrix eBioscience (San Diego, Calif., USA). The IL- $1 \beta$ and IL-18 ELISAs measured the active forms of these cytokines and not the propeptide forms [42].

\section{Murine ELISA for Albumin Measurement}

BALF albumin (albumin quantification kit; Bethyl Laboratories, Montgomery, Tex., USA) for lung permeability assessment was quantified using a modified double-ligand method.

Nitric Oxide Analysis

Nitric oxide levels in PM supernatants were analyzed using a standard Griess assay [42].

Flagellin Stimulates Protective Immunity

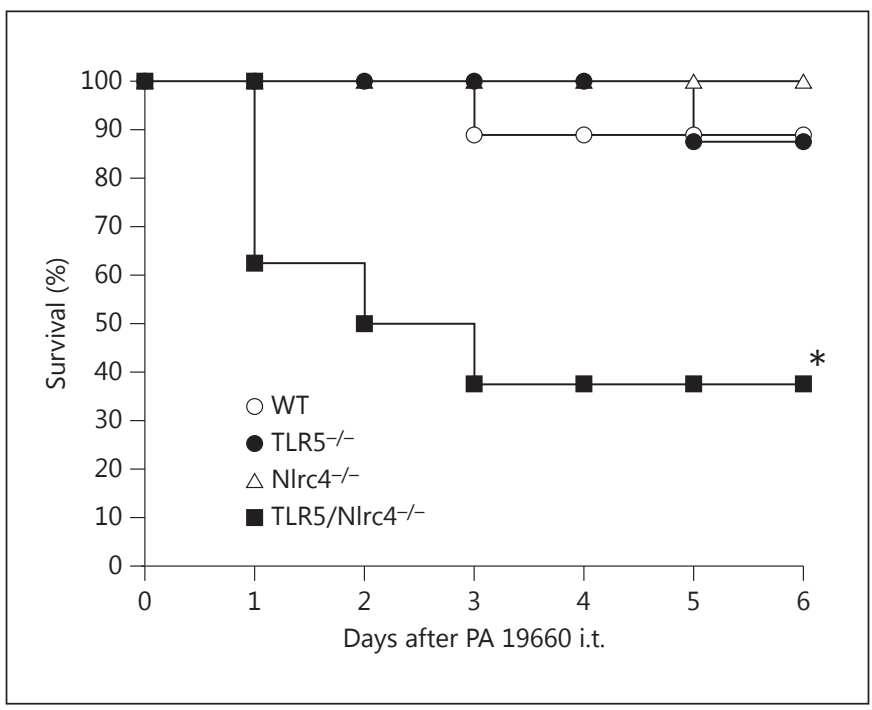

Fig. 1. Effect of TLR5, Nlrc4 or TLR5/Nlrc4 gene deletion on survival after i.t. PA challenge. Mice were administered $7 \times 10^{5} \mathrm{CFU}$ i.t., and then survival was assessed up to 6 days. Results shown are combined from two separate experiments; $n=8-10$ mice per group. ${ }^{*} \mathrm{p}<0.05$ as compared to the other groups.

\section{Real-Time Quantitative RT-PCR}

Measurements of gene expression were performed utilizing the ABI Prism 7000 sequence detection system (Applied Biosystems, Foster City, Calif., USA) as previously described. Briefly, total cellular RNA from frozen lung samples was isolated, reverse transcribed into cDNA, and then amplified using specific primers for IL- $1 \beta$ and iNOS (NOS2) with $\beta$-actin serving as an internal control. Specific thermal cycling parameters used with the TaqMan onestep RT-PCR master mix reagents kit are as follows: $30 \mathrm{~min}$ at $48^{\circ} \mathrm{C}$, $10 \mathrm{~min}$ at $95^{\circ} \mathrm{C}$, and 40 cycles involving denaturation at $95^{\circ} \mathrm{C}$ for $15 \mathrm{~s}$ and annealing/extension at $60^{\circ} \mathrm{C}$ for $1 \mathrm{~min}$. The relative quantification of cytokine mRNA levels was plotted as the fold change compared with untreated control cells or whole lung [41].

\section{Statistical Analysis}

Survival curves were compared using log-rank (Mantel-Cox) tests. Statistical significance was determined by using one-way ANOVA. All calculations were performed using GraphPad Prism 6.0 software for Windows (GraphPad Software, La Jolla, Calif., USA).

\section{Results}

\section{Genetic Deletion of TLR5 and Nlrc4 in Combination}

Results in Reduced Survival and Impaired Bacterial

Clearance after i.t. Administration of $P A$

To determine the role that TLR5 and Nlrc4 alone or in combination play in the innate immune response to flagellated Gram-negative bacteria, WT mice and mice lacking the genes for TLR5 (TLR5 ${ }^{-/-}, \mathrm{Nlrc} 4\left(\mathrm{Nlrc}_{4}{ }^{-/}\right)$, or mice 

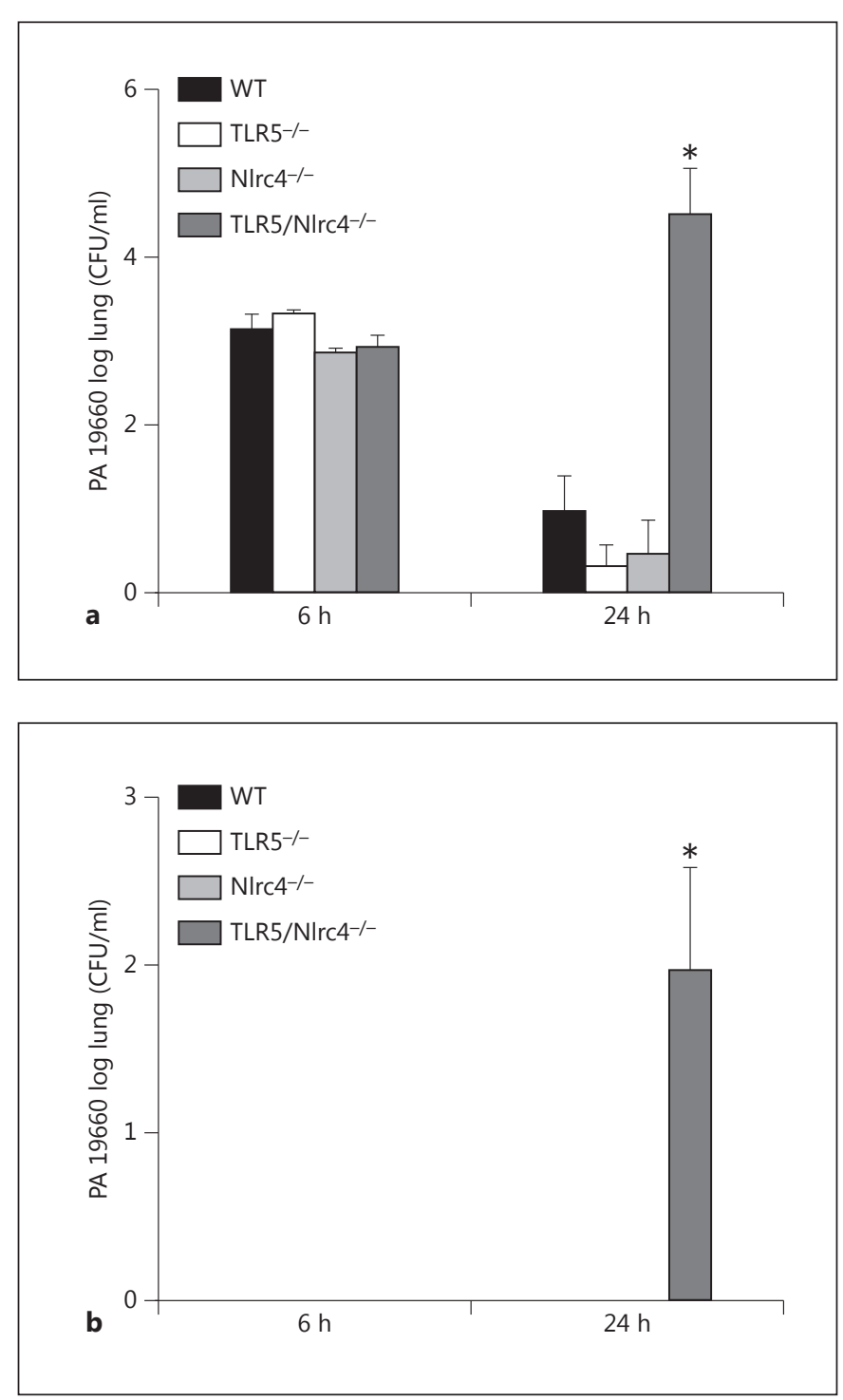

Fig. 2. Effect of TLR5, Nlrc4 or TLR5/Nlrc4 gene deletion on lung and spleen PA CFU after i.t. PA challenge. Mice were administered $5 \times 10^{5} \mathrm{CFU}$ i.t., and then PA CFU were quantitated in lung (a) and spleen (b) $24 \mathrm{~h}$ later. Data are expressed as $\log _{10}$, combined from two separate experiments; $\mathrm{n}=6-8$ per group. ${ }^{*} \mathrm{p}<0.0001$ as compared to the other groups.

deficient in both (TLR5/Nlrc4 $4^{-/}$) were i.t. administered PA strain $19660(\mathrm{PA})$ at a dose of $7 \times 10^{5} \mathrm{CFU} / 30 \mu \mathrm{l}$ and monitored for 6 days. As shown in figure 1, survival was $>85 \%$ in WT or single-mutant mice. By comparison, survival was $<40 \%$ in similarly challenged TLR5/Nlrc4 ${ }^{-/}$ mice $(\mathrm{p}<0.05)$. No deaths were observed after 6 days.

We next determined if the differences in mortality observed were attributable to alterations in bacterial clearance. For these experiments, PA was administered at a
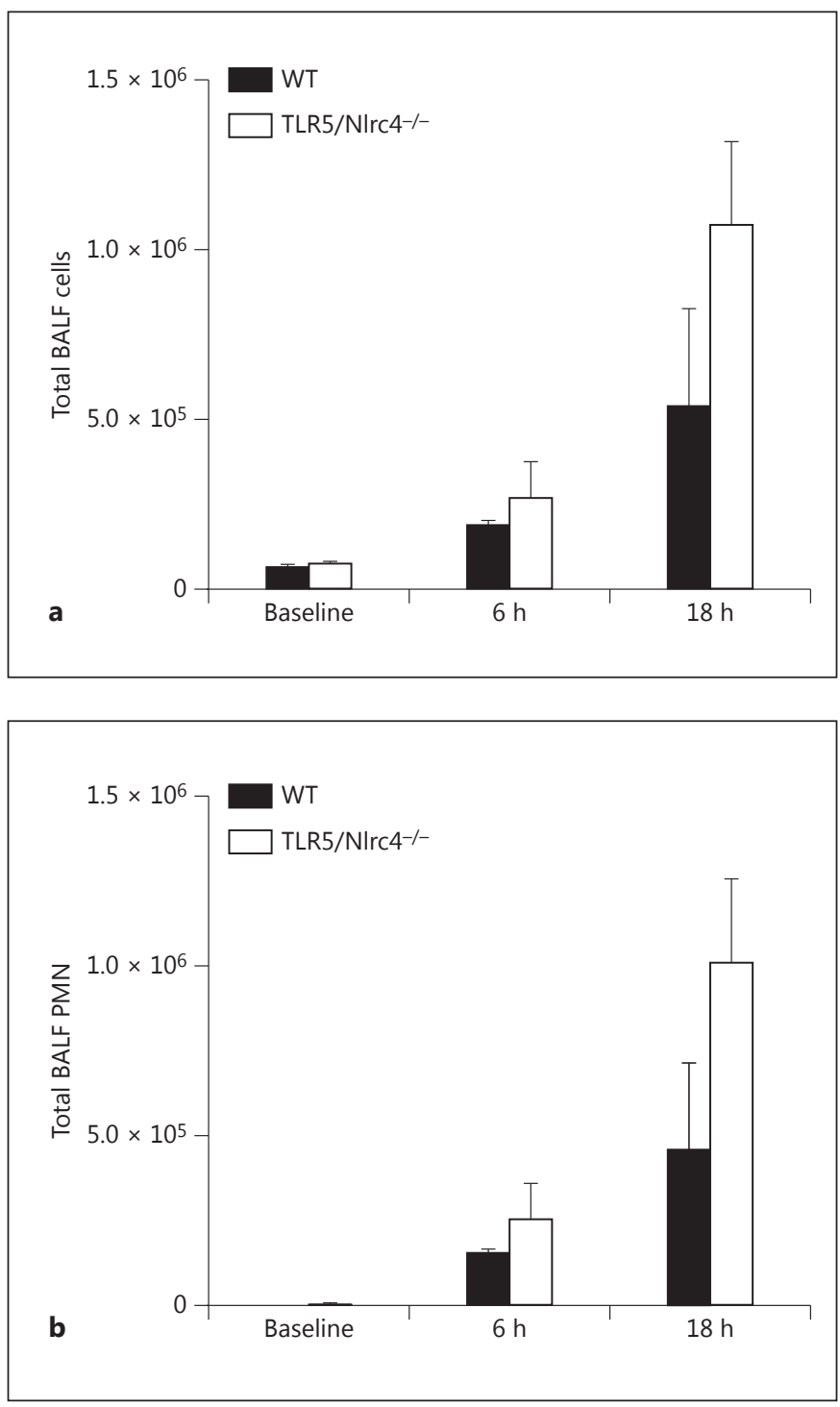

Fig. 3. Effect of TLR5/Nlrc4 gene deletion on total BALF cells (a) and BALF PMN (b) after PA challenge. Mice were administered $5 \times 10^{5} \mathrm{CFU}$ i.t., and then total cells and PMN were quantitated at 6 and $18 \mathrm{~h}$ postchallenge; $n=4-6$ per group.

dose of $5 \times 10^{5} \mathrm{CFU}$ to WT, $\mathrm{TLR}^{-/-}, \mathrm{Nlrc}^{-/-}$and TLR5/ $\mathrm{Nlrc} 4^{-/-}$mice, then lungs and spleen were harvested 6 and $24 \mathrm{~h}$ after instillation and CFU quantified. We observed no differences in lung CFU in the 4 groups at $6 \mathrm{~h}$ postchallenge, and no animals were bacteremic at that time point (fig. 2a, b). At $24 \mathrm{~h}$, lung CFU were low in WT and single-deficient mice ( $<50 \mathrm{CFU})$, and no differences between groups were noted. In contrast, there was persistence of bacteria in the infected TLR5/ $\mathrm{Nlrc}^{-/-}$mice, rep- 
resenting a $>3.5 \log$ increase, as compared to WT mice ( $p<0.0001$; fig. 2a). Likewise, there was a substantial increase in spleen CFU in TLR5/Nlrc4 ${ }^{-/-}$mice (fig. 2b), whereas no splenic dissemination was observed in either WT or single-mutant mice. Importantly, as compared to WT mice, there were no significant differences in the number of BAL total cells or neutrophils in the doubledeficient mice at either 6 or $18 \mathrm{~h}$ after PA, indicating that the impairment in bacterial clearance observed in TLR5/ Nlrc $4^{-/-}$mice was not attributable to differences in lung inflammatory cell influx (fig. 3).

\section{Differences in Bacterial Clearance and Survival of}

TLR5/Nlrc4 ${ }^{-/-}$Mice after i.t. PA Challenge were not

Attributable to Lung Injury

Bacterial pneumonia is a common cause of acute lung injury, which contributes to morbidity and mortality associated with pneumonia due to PA. As a surrogate for capillary leak, cell-free BALF albumin was measured 6 and $18 \mathrm{~h}$ after i.t. administration of PA $\left(5 \times 10^{5} \mathrm{CFU} / 30\right.$ $\mu \mathrm{l})$ in $\mathrm{WT}$, single- and double-mutant mice. As shown in figure 4, i.t. challenge with PA resulted in an increase in BAL albumin levels by $6 \mathrm{~h}$, which was maximally increased by $18 \mathrm{~h}$ after PA administration. As compared to WT animals, we noted no difference in BALF albumin at 6 or $18 \mathrm{~h}$ postinfection in $\mathrm{TLR}^{-/-}$or TLR5/ $\mathrm{Nlrc}^{-/-}$mice. Interestingly, BAL albumin levels were significantly reduced in Nlrc4 ${ }^{-/-}$mice at both 6 and $18 \mathrm{~h}$ compared to other groups ( $\mathrm{p}<0.01$ at both time points).

\section{Selective Reduction in Inflammatory Cytokines and \\ Chemokines in Single- and Double-Mutant Mice \\ following i.t. Administration of PA}

Both TLR5 and Nlrc4 pathways have been shown to regulate the expression of cytokines and chemokines in the setting of bacterial infection. Nlrc4-mediated inflammasome activation also regulates the posttranslational conversion of pro-IL- $1 \beta$ and pro-IL- 18 to their active metabolites in a caspase-1-dependent fashion [28]. For that reason, we measured TNF- $\alpha$, CXCL1/KC, IL- $1 \beta$ and IL18 levels in cell-free BALF collected from WT and mutant mice at $18 \mathrm{~h}$ after PA administration. We chose this time point as cytokine/chemokine levels peaked at $18 \mathrm{~h}$. We observed no differences in BALF TNF levels of WT, single- or double-mutant mice after PA challenge (fig. 5a). Conversely, KC/CXCL1 levels in BALF were significantly reduced in $\mathrm{TLR}^{-/-}$, $\mathrm{Nlrc}^{-/-}$and TLR5/Nlrc4 ${ }^{-/-}$mice as compared to infected WT mice. Levels of IL- $1 \beta$ were low at baseline in all groups, with a large increase in BALF IL$1 \beta$ by $18 \mathrm{~h}$ after PA in the WT and TLR $5^{-/}$single-mutant

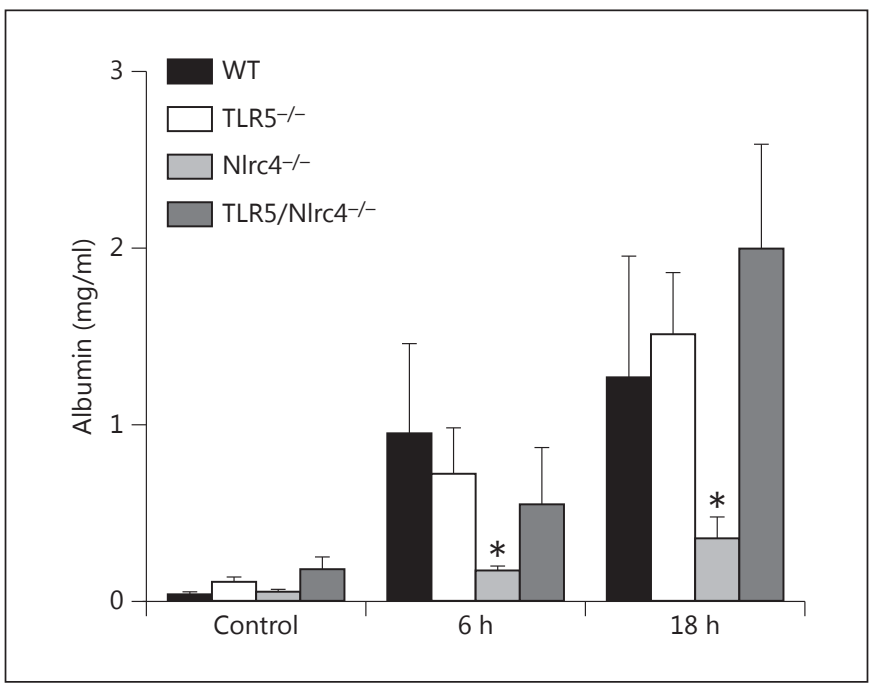

Fig. 4. Effect of TLR5, Nlrc4 or TLR5/Nlrc4 gene deletion on BALF albumin levels. Mice were administered $5 \times 10^{5} \mathrm{CFU}$ i.t., and then BALF albumin levels were quantitated at 6 and $18 \mathrm{~h}$ postchallenge; $\mathrm{n}=4-6$ per group. ${ }^{*} \mathrm{p}<0.01$ as compared to other groups.

mice. However, we observed no increase in BALF IL- $1 \beta$ levels in $\mathrm{Nlrc}^{-/-}$and TLR5/Nlrc4 ${ }^{-/-}$double-deficient mice after PA administration (fig. 5a). Similarly, we observed a marked increase in BALF IL-18 levels in infected $\mathrm{WT}$ and TLR5 ${ }^{-/-}$mice, but only a minimal increase in IL18 levels was noted in $\mathrm{Nlrc}^{-/-}$and TLR5/Nlrc4 ${ }^{-/}$double-deficient mice $18 \mathrm{~h}$ after PA challenge.

In addition to the aforementioned cytokines, we also measured mRNA and protein expression of other important innate effector molecules in infected WT, TLR5 ${ }^{-1-}$, $\mathrm{Nlrc}^{-/-}$and TLR5/Nlrc4 ${ }^{-/-}$mice. Specifically, we assessed the mRNA expression of IL-17 and IL-22 in whole lungs of WT and mutant mice at both 6 and $18 \mathrm{~h}$ after PA administration and found no differences in any of the groups (data not shown). We also measured IL-17 in cellfree BALF at $18 \mathrm{~h}$ after PA administration and found no significant differences. Finally, we measured CRAMP mRNA expression (RT-PCR) and protein (by Western blotting) at both 6 and $18 \mathrm{~h}$ in WT, single- and doublemutant mice and detected no differences (data not shown).

PM Produce IL-1 $\beta$ in an Nlrc4-Dependent Fashion, whereas Maximal Expression of $i N O S$ and NO Requires Cooperative Effects of TLR5 and Nlrc4

$\mathrm{PM}$ are a major early cellular source of inflammatory cytokines and the antimicrobial molecule $\mathrm{NO}$ in response to bacterial invasion. To assess the impact of TLR5 and/ 


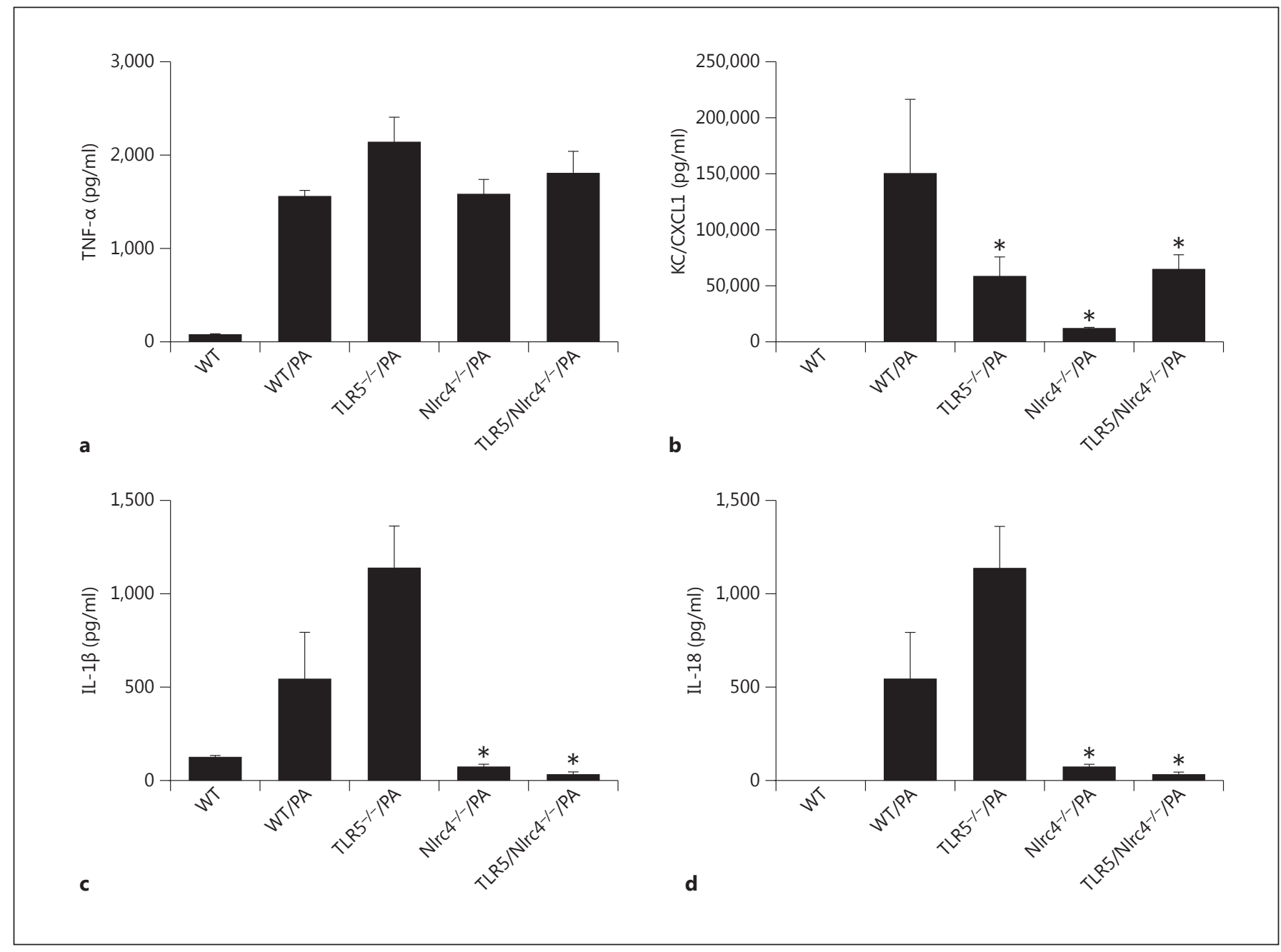

Fig. 5. Effect of TLR5, Nlrc4 or TLR5/Nlrc4 gene deletion on BALF cytokine/chemokine levels. Mice were administered $5 \times 10^{5} \mathrm{CFU}$ i.t., and then BALF TNF- $\alpha$ (a), KC/CXCL1 (b), IL-1 $\beta$ (c) and IL-18 (d) levels were quantitated by ELISA at $18 \mathrm{~h}$ postchallenge; $\mathrm{n}=4-6$ per group. ${ }^{*} \mathrm{p}<0.05$ as compared to infected WT control mice. or Nlrc4 deficiency on the expression of IL- $1 \beta$ and NO from PM in vitro, we isolated PM from uninfected WT and mutant mice, and then stimulated cells with live PA (MOI 5:1). Cells were isolated for RNA and cell-free conditioned media collected after 6 or $18 \mathrm{~h}$ in culture, then assayed for IL- $1 \beta$ or iNOS mRNA levels (fig. 6a) and cytokine protein or NO levels (fig. 6b). Maximal induction of IL-1 $\beta$ mRNA expression in PM from WT mice was noted $6 \mathrm{~h}$ after PA. We observed no significant reduction in IL- $1 \beta$ mRNA levels in PM from single- or doublemutant mice. In contrast, there was a substantial reduction in active IL- $1 \beta$ release by PA-stimulated PM from $\mathrm{Nlrc}^{-/-}$and TLR5/Nlrc4 ${ }^{-/-}$double-deficient mice, as compared to WT and $\mathrm{TLR}^{-/-} \mathrm{PM}$. The expression of iNOS mRNA was maximal at $18 \mathrm{~h}$ after PA in WT PM, and significant reductions were observed in cells from TLR5/ $/ \mathrm{Nlc}^{-/-}$mice and a trend toward reduced expression in PM from $\mathrm{TLR}^{-/-}$mice $(\mathrm{p}=0.06)$. Release of NO from stimulated cells was strongly induced by PA $(>40$ fold increase), but only significantly reduced in PM from double-mutant mice.

To further explore mechanisms of impaired IL- $1 \beta$ release in single- and/or double-mutant mice, we examined the activation of caspases- 1 , the protease responsible for cleavage of IL-1 $\beta$ and IL-18 propeptide to active forms. Stimulation of PM with PA resulted in abundant accumu- 

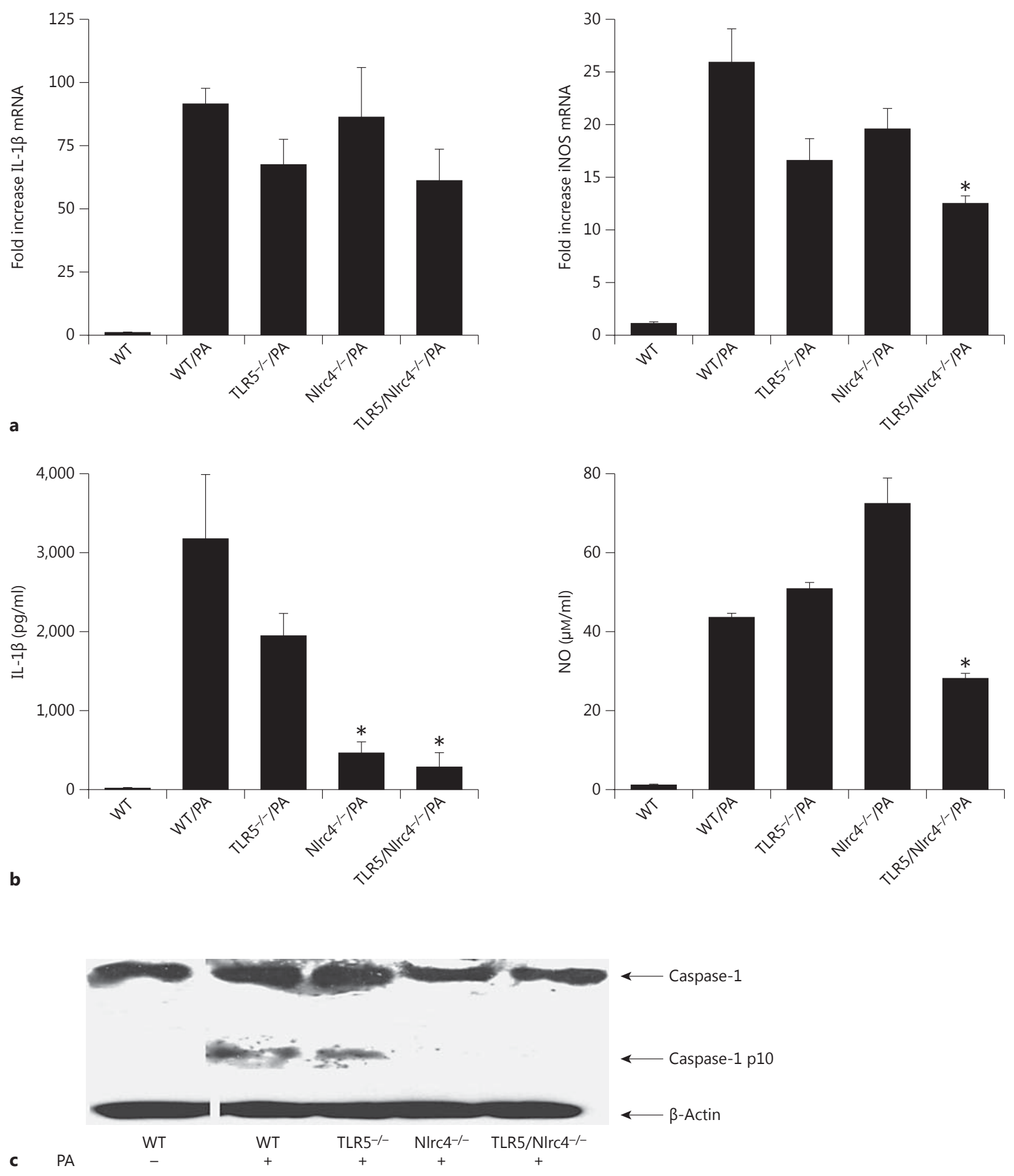

Fig. 6. Effect of TLR5, Nlrc4 or TLR5/Nlrc4 gene deletion on the expression of IL-1 $\beta$, NO and caspase- 1 activation in PA-stimulated PM in vitro. Expression of IL-1 $\beta$ and iNOS mRNA (a), levels of IL- $\beta$ and NO in PM-conditioned media (b), and amount of total and active (p10) forms of caspase- 1 by Western blotting $(\mathbf{c}) . \mathrm{n}=$ 4-6 per group for mRNA and protein studies, whereas Western blotting is representative of 2 separate experiments. ${ }^{*} \mathrm{p}<0.05$ as compared to PM from WT mice. 
lation of the cleaved $10 \mathrm{kDa}$ form of caspase- 1 in WT and $\mathrm{TLR}^{-/-}$macrophages (fig. 6c). Interestingly, no active caspase-1 was detected in PM from either $\mathrm{Nlrc}^{-/-}$or TLR5/Nlrc4 ${ }^{-/-}$double-mutant mice.

\section{Discussion}

Our study demonstrates that effective antibacterial responses to i.t. administration of PA require the presence of either TLR5 or Nlrc4, and the presence of one of these PRRs can compensate for the absence of the other. However, mice that are deficient in both TLR5 and Nlrc4 display substantially reduced survival and impaired bacterial clearance as compared to their WT or single-mutant counterparts. The differences in bacterial clearance could not be explained based on differences in inflammatory cell recruitment or the expression of key innate cytokines, including TNF- $\alpha$, chemokines and IL-1 family cytokines.

TLR5 and Nlrc4 have previously been shown to be important PRRs recognizing bacterial flagellin [43, 44]. While TLR5 exclusively binds extracellular flagellin, Nlrc4 has been shown to be activated by intracellular flagellin. In addition, Nlrc4 is activated by components of the type III secretion system, leading to downstream inflammasome activation [36]. Our data suggest that TLR5 and Nlrc 4 can independently regulate the expression of the $\mathrm{CXC}$ chemokine $\mathrm{KC} / \mathrm{CXCL1}$, whereas the generation of biologically active IL-1 $\beta$ and IL-18 is solely Nlrc4 dependent and completely independent of TLR5. Impaired production of chemokines, including $\mathrm{KC} / \mathrm{CXCL} 1$, has been observed in Nlrc4 but not TLR5 single-deficient mice during Gram-negative bacterial pneumonia [23, 40, 45 ]. The finding of unaltered mRNA expression but substantially reduced IL- $1 \beta$ release and caspase- 1 activation in in vitro stimulated PM from Nlrc4- and TLR5/Nlrc4deficient mice strongly suggests that the reduction in IL$1 \beta$ and IL-18 in BALF is entirely mediated by Nlrc4-dependent propeptide processing. By comparison, it does appear that the full induction of iNOS and production of NO by PA-stimulated PM requires the cooperative effects of both TLR5 and Nlrc4. These PRRs have been independently shown to contribute to the induction of iNOS, and recent data indicate that this induction requires caspase-1 [46].

The differences in mortality observed were not attributable to differential lung injury responses, as we observed similar increases in BAL albumins at both 6 and 18 $h$. An interesting observation was that reduced lung injury was observed in Nlrc4-deficient mice after PA ad- ministration, as compared to WT, TLR $5^{-/-}$or TLR5/ $\mathrm{Nlrc}^{-/-}$mice. Indeed, $\mathrm{Nlrc}^{-/-}$mice were protected from the lethal effects of PA when challenged with an $\mathrm{LD}_{80}$ inoculum of PA [unpublished observation]. These findings are in line with recent observations by Cohen and Prince [39], who found protection from lung injury and reduced mortality in Nlrc4-deficient mice after i.t. challenge with a cytotoxic PA strain, an effect which was attributed to reduced secretion of biologically active IL- $1 \beta$ and IL-18. Conversely, activation of TLR5 has been shown to prevent alveolar epithelial cell apoptosis and high permeability edema in models of both infectious and noninfectious lung injury $[47,48]$. The lung injury response found in our double-mutant mice mimics that observed in $\mathrm{TLR}^{-1-}$ single-mutant mice, suggesting the phenotype observed is dictated by the TLR5-mediated effects, presumably on alveolar epithelium.

The mechanism accounting for impaired lung bacterial clearance in TLR5/Nlrc4 $4^{--}$mice has not been precisely defined. There was a substantial reduction in IL- $1 \beta$ and IL-18 in double-deficient mice. However, the defect in these cytokines was of similar magnitude in $\mathrm{Nlrc}^{-/-}$ mice, which demonstrated no defect in clearance responses. Moreover, we were unable to restore immunity in TLR5/ $\mathrm{Nlrc}^{-/-}$double-deficient mice by the reconstitution of IL- $1 \beta$ or IL-18 alone or in combination ( $500 \mathrm{ng}$ i.t. or i.p.; data not shown). We also observed reduced KC/CXCL1 expression in mutant mice, but this defect was not greater in double-mutant mice as compared to their single-mutant counterparts, and for unclear reasons reduced chemokine production was not associated with impaired polymorphonuclear neutrophils (PMN) or total cell influx at either 6 or $18 \mathrm{~h}$ after PA (fig. 3). The one effector molecule that was more substantially reduced in $\mathrm{PM}$ from TLR5/Nlrc4 ${ }^{-/-}$mice was NO, which was due, in part, to reduced expression of iNOS. Nitric oxide is a welldescribed antimicrobial molecule against bacterial pathogens, including Gram-negative organisms, and we have shown that inhibition of NO production can worsen lung bacterial clearance in experimental murine K. pneumoniae pneumonia in vivo [42]. While a defect in NO production in PM-conditioned media from double-knockout mice was noted in vitro, we were unable to confirm this in vivo, as NO could not be detected in BALF from either control or infected WT or mutant mice (data not shown).

Our finding of unaltered bacterial clearance in $\mathrm{Nlrc}^{-/-}$mice infected with PA is consistent with the observation of others [39]. In contrast, mice deficient in Nlrc4 are more susceptible to another Gram-negative organism, K. pneumoniae [40]. The pathogen-specific 
differences are likely accounted for by the more virulent nature of $K$. pneumoniae, which is a heavily encapsulated organism that requires a fully intact innate immune response, including both PMN, alveolar and recruited macrophages for optimal clearance. Conversely, PA is an unencapsulated, less virulent organism that is generally cleared by resident lung macrophages unless multiple defects in immune mechanisms are disrupted. Regardless, our findings indicate a largely redundant role for TLR5 and Nlrc4 in lung mucosal innate immunity against PA, and only in the absence of both does one observe a defect in host immunity.

\section{Acknowledgements}

This study was supported by NIH/NHLBI grants HL97546 (T.J.S.), HL25243 (T.J.S.), EY17960 (F.Y.) and EY10869 (F.Y.).

\section{References}

-1 American Thoracic Society, Infectious Diseases Society of America: Guidelines for the management of adults with hospital-acquired, ventilator-associated, and healthcareassociated pneumonia. Am J Resp Crit Care Med 2005; 171:388-416.

$\checkmark 2$ Carratala J, Mykietiuk A, Fernandez-Sabe N, Suarez C, Dorca J, Verdaguer R, et al: Health care-associated pneumonia requiring hospital admission: epidemiology, antibiotic therapy, and clinical outcomes. Arch Int Med 2007; 167:1393-1399.

3 Kollef MH, Shorr A, Tabak YP, Gupta V, Liu LZ, Johannes RS: Epidemiology and outcomes of health-care-associated pneumonia: results from a large US database of culturepositive pneumonia. Chest 2005;128:38543862.

-4 Micek ST, Kollef KE, Reichley RM, Roubinian N, Kollef MH: Health care-associated pneumonia and community-acquired pneumonia: a single-center experience. Antimicrob Agents Chemother 2007;51:3568-3573.

$\checkmark 5$ Shindo Y, Sato S, Maruyama E, Ohashi T, Ogawa M, Hashimoto N, et al: Health-careassociated pneumonia among hospitalized patients in a Japanese community hospital. Chest 2009; 135:633-640.

6 Venditti M, Falcone M, Corrao S, Licata G, Serra P: Outcomes of patients hospitalized with community-acquired, health care-associated, and hospital-acquired pneumonia. Ann Intern Med 2009;150:19-26.

7 Mandell GL, Bennett JE, Dolin R: Mandell, Douglas, and Bennett's Principles and Practice of Infectious Diseases. Philadelphia, Churchill Livingstone, 2010.

$>8$ Rello J, Ollendorf DA, Oster G, Vera-Llonch M, Bellm L, Redman R, et al: Epidemiology and outcomes of ventilator-associated pneumonia in a large US database. Chest $2002 ; 122$ : 2115-2121.

9 Faure K, Sawa T, Ajayi T, Fujimoto J, Moriyama $\mathrm{K}$, Shime N, et al; TLR4 signaling is essential for survival in acute lung injury induced by virulent Pseudomonas aeruginosa secreting type III secretory toxins. Respir Res 2004;5:1.
10 Hauser AR, Cobb E, Bodi M, Mariscal D, Valles J, Engel JN, et al: Type III protein secretion is associated with poor clinical outcomes in patients with ventilator-associated pneumonia caused by Pseudomonas aeruginosa. Crit Care Med 2002;30:521-528.

11 Sawa T, Corry DB, Gropper MA, Ohara M, Kurahashi K, Wiener-Kronish JP: IL-10 improves lung injury and survival in Pseudomonas aeruginosa pneumonia. J Immunol 1997; 159:2858-2866

12 Aderem A, Ulevitch RJ: Toll-like receptors in the induction of the innate immune response. Nature 2000;406:782-787.

13 Akira S, Hemmi H: Recognition of pathogenassociated molecular patterns by TLR family. Immunol Lett 2003;85:85-95.

-14 An H, Yu Y, Zhang M, Xu H, Qi R, Yan X, et al: Involvement of ERK, p38 and NF- $\kappa$ B signal transduction in regulation of TLR2, TLR4 and TLR9 gene expression induced by lipopolysaccharide in mouse dendritic cells. Immunology 2002;106:38-45.

15 Hajjar AM, Ernst RK, Tsai JH, Wilson CB, Miller SI: Human Toll-like receptor 4 recognizes host-specific LPS modifications. Nat Immunol 2002;3:354-359.

$>16$ Harshey RM, Toguchi A: Spinning tails: homologies among bacterial flagellar systems. Trends Microbiol 1996;4:226-231.

17 Andersen-Nissen E, Smith KD, Bonneau R, Strong RK, Aderem A: A conserved surface on Toll-like receptor 5 recognizes bacterial flagellin. J Exp Med 2007;204:393-403.

18 Feuillet V, Medjane S, Mondor I, Demaria O, Pagni PP, Galan JE, et al: Involvement of Tolllike receptor 5 in the recognition of flagellated bacteria. Proc Natl Acad Sci USA 2006;103: 12487-12492

19 Gewirtz AT, Navas TA, Lyons S, Godowski PJ, Madara JL: Cutting edge: bacterial flagellin activates basolaterally expressed TLR5 to induce epithelial proinflammatory gene expression. J Immunol 2001;167:1882-1885.

20 Hayashi F, Smith KD, Ozinsky A, Hawn TR, Yi EC, Goodlett DR, et al: The innate immune response to bacterial flagellin is mediated by Toll-like receptor 5. Nature 2001;410:10991103.
21 Sebastiani G, Leveque G, Lariviere L, Laroche L, Skamene E, Gros P, et al: Cloning and characterization of the murine Toll-like receptor 5 (Tlr5) gene: sequence and mRNA expression studies in Salmonella-susceptible MOLF/Ei mice. Genomics 2000;64:230-240.

22 Adamo R, Sokol S, Soong G, Gomez MI, Prince A: Pseudomonas aeruginosa flagella activate airway epithelial cells through asialoGM1 and toll-like receptor 2 as well as toll-like receptor 5. Am J Respir Cell Mol Biol 2004;30:627-634.

23 Skerrett SJ, Wilson CB, Liggitt HD, Hajjar AM: Redundant Toll-like receptor signaling in the pulmonary host response to Pseudomonas aeruginosa. Am J Physiol Lung Cell Mol Physiol 2007;292:L312-L322.

24 Zhang Z, Louboutin JP, Weiner DJ, Goldberg JB, Wilson JM: Human airway epithelial cells sense Pseudomonas aeruginosa infection via recognition of flagellin by Toll-like receptor 5 . Infect Immun 2005;73:7151-7160.

-25 Gu Y, Kuida K, Tsutsui H, Ku G, Hsiao K, Fleming MA, et al: Activation of interferon- $\gamma$ inducing factor mediated by interleukin-1 $\beta$ converting enzyme. Science 1997;275:206209.

26 Cogswell JP, Godlevski MM, Wisely GB, Clay WC, Leesnitzer LM, Ways JP, et al: NF- $\mathrm{BB}$ regulates IL- $1 \beta$ transcription through a consensus NF- $\kappa \mathrm{B}$ binding site and a nonconsensus CRE-like site. J Immunol 1994;153:712723.

-27 Tallant T, Deb A, Kar N, Lupica J, de Veer MJ, DiDonato JA: Flagellin acting via TLR5 is the major activator of key signaling pathways leading to NF- $\mathrm{KB}$ and proinflammatory gene program activation in intestinal epithelial cells. BMC Microbiol 2004;4:33

28 Sollberger G, Strittmatter GE, Garstkiewicz M, Sand J, Beer HD: Caspase-1: the inflammasome and beyond. Innate Immun 2014;20: 115-125

29 Miao EA, Alpuche-Aranda CM, Dors M, Clark AE, Bader MW, Miller SI, et al: Cytoplasmic flagellin activates caspase- 1 and secretion of interleukin $1 \beta$ via Ipaf. Nat Immunol 2006;7:569-575. 
30 Pandey AK, Yang Y, Jiang Z, Fortune SM, Coulombe F, Behr MA, et al: NOD2, RIP2 and IRF5 play a critical role in the type I interferon response to Mycobacterium tuberculosis. PLoS Pathog 2009;5:e1000500.

-31 Martinon F, Mayor A, Tschopp J: The inflammasomes: guardians of the body. Annu Rev Immunol 2009;27:229-265.

-32 Franchi L, Park JH, Shaw MH, Marina-Garcia N, Chen G, Kim YG, et al: Intracellular NODlike receptors in innate immunity, infection and disease. Cell Microbiol 2008;10:1-8.

33 Monack DM: Immunology: recognition of a unique partner. Nature 2011;477:543-544.

- 34 Sirard JC, Vignal C, Dessein R, Chamaillard M: Nod-like receptors: cytosolic watchdogs for immunity against pathogens. PLoS Pathog 2007;3:e152.

35 Miao EA, Mao DP, Yudkovsky N, Bonneau R, Lorang CG, Warren SE, et al: Innate immune detection of the type III secretion apparatus through the NLRC4 inflammasome. Proc Natl Acad Sci USA 2010;107:3076-3080.

- 36 Franchi L, Stoolman J, Kanneganti TD, Verma A, Ramphal R, Nunez G: Critical role for Ipaf in Pseudomonas aeruginosa-induced caspase-1 activation. Eur J Immunol 2007;37: 3030-3039.
Kofoed EM, Vance RE: Innate immune recognition of bacterial ligands by NAIPs determines inflammasome specificity. Nature 2011;477:592-595.

38 Zhao Y, Yang J, Shi J, Gong YN, Lu Q, Xu H, et al: The NLRC4 inflammasome receptors for bacterial flagellin and type III secretion apparatus. Nature 2011;477:596-600.

39 Cohen TS, Prince AS: Activation of inflammasome signaling mediates pathology of acute $P$. aeruginosa pneumonia. J Clin Invest 2013;123:1630-1637.

40 Cai S, Batra S, Wakamatsu N, Pacher P, Jeyaseelan S: NLRC4 inflammasome-mediated production of IL-1 $\beta$ modulates mucosal immunity in the lung against Gram-negative bacterial infection. J Immunol 2012;188: 5623-5635.

41 Deng JC, Cheng G, Newstead MW, Zeng X, Kobayashi K, Flavell RA, et al: Sepsis-induced suppression of lung innate immunity is mediated by IRAK-M. J Clin Invest 2006;116: 2532-2542.

42 Tsai WC, Strieter RM, Zisman DA, Wilkowski JM, Bucknell KA, Chen GH, et al: Nitric oxide is required for effective innate immunity against Klebsiella pneumoniae. Infect Immun 1997;65:1870-1875.
43 Miao EA, Andersen-Nissen E, Warren SE, Aderem A: TLR5 and Ipaf: dual sensors of bacterial flagellin in the innate immune system. Semin Immunopathol 2007;29:275-288.

44 Vijay-Kumar M, Carvalho FA, Aitken JD, Fifadara NH, Gewirtz AT: TLR5 or NLRC4 is necessary and sufficient for promotion of humoral immunity by flagellin. Eur J Immunol 2010;40:3528-3534.

45 Morris AE, Liggitt HD, Hawn TR, Skerrett SJ: Role of Toll-like receptor 5 in the innate immune response to acute $P$. aeruginosa pneumonia. Am J Physiol Lung Cell Mol Physiol 2009;297:L1112-L1119.

46 Buzzo CL, Campopiano JC, Massis LM, Lage SL, Cassado AA, Leme-Souza R, et al: A novel pathway for inducible nitric-oxide synthase activation through inflammasomes. J Biol Chem 2010;285:32087-32095.

47 Yu FS, Cornicelli MD, Kovach MA, Newstead MW, Zeng X, Kumar A, et al: Flagellin stimulates protective lung mucosal immunity: role of cathelicidin-related antimicrobial peptide. J Immunol 2010;185:1142-1149.

48 Wang ZD, Qiao YL, Tian XF, Zhang XQ, Zhou SX, Liu HX, et al: Toll-like receptor 5 agonism protects mice from radiation pneumonitis and pulmonary fibrosis. Asian Pac J Cancer Prev 2012;13:4763-4767. 